\title{
Management and Therapy for Pulmonary Hypertension: 2016 Update
}

\author{
Simone K. Visser, MBBS, BPharm¹, Marc Humbert, MD, PhD² and Edmund M. Lau, MD, PhD'1
}

${ }^{1}$ University of Sydney, Sydney Medical School, Department of Respiratory Medicine, Royal Prince Alfred Hospital, Camperdown, Australia; ${ }^{2}$ University Paris-Sud, Faculté de Médecine and AP-HP, Centre de Référence de l'Hypertension Pulmonaire Sévère, Département Hospitalo-Universitaire (DHU) Thorax Innovation (TORINO), Service de Pneumologie, Hôpital de Bicêtre, Le Kremlin Bicêtre, France; UMR_S 999, University Paris-Sud; INSERM; Laboratoire d'Excellence (LabEx) en Recherche sur le Médicament et l'Innovation Thérapeutique (LERMIT), Centre Chirurgical Marie Lannelongue, Le Plessis Robinson, France

\section{ABSTRACT}

Pulmonary hypertension encompasses a range of conditions that lead through varying mechanisms to an elevated mean pulmonary artery pressure of $\geq 25 \mathrm{mmHg}$ at right heart catheterization. This update on pulmonary hypertension management will focus on those areas in which major recent developments have occurred, specifically pulmonary arterial hypertension and chronic thromboembolic pulmonary hypertension. An increasing repertoire of approved targeted medical therapies and data supporting the efficacy of combination therapy have transformed the management algorithm for pulmonary arterial hypertension, which has recently been updated in the 2015 European Society of Cardiology/European Respiratory Society guidelines. For patients with chronic thromboembolic pulmonary hypertension, pulmonary endarterectomy remains the treatment of choice. However, treatment options for those with adjudicated inoperable or persistent/recurrent chronic thromboembolic pulmonary hypertension have expanded. Riociguat has demonstrated efficacy and is approved for these patients, and balloon pulmonary angioplasty is being offered at an increasing number of expert centres worldwide. (BRN Rev. 2016;2:114-28) Corresponding author: Edmund Lau,edmund.lau@sydney.edu.au

Key words: Chronic thromboembolic disease. Pulmonary arterial hypertension. Pulmonary hypertension.

\section{Correspondence to:}

Edmund Lau

Department of Respiratory and Sleep Medicine

Royal Prince Alfred Hospital 


\section{INTRODUCTION}

Pulmonary hypertension (PH) is an abnormal haemodynamic state of the pulmonary circulation defined by an elevated resting mean pulmonary artery pressure (mPAP) of $\geq 25 \mathrm{mmHg}$ at right heart catheterisation ${ }^{1}$. Pulmonary hypertension is further stratified as pre-capillary when the pulmonary artery wedge pressure (PAWP) is $\leq 15 \mathrm{mmHg}$ or post-capillary when PAWP is $>15 \mathrm{mmHg}^{2}$. Pulmonary hypertension can develop as the consequence of many distinct disease entities, and the current clinical classification divides $\mathrm{PH}$ into five separate subgroups based on shared pathophysiology, clinical features, and therapeutic approach (Table 1) $)^{1,3}$.

Group 1 pulmonary arterial hypertension (PAH) is comprised of a group of rare conditions where the primary abnormality is a vasculopathy affecting the distal pulmonary arteries ${ }^{4}$. Modern trials of "targeted" pulmonary vasodilator therapies have evaluated mainly patients with Group $1 \mathrm{PAH}$, where an increasing number of randomised controlled trial (RCT) data have been accumulated over the past two decades to support the efficacy of these agents in improving exercise capacity, quality of life, and clinical outcomes ${ }^{4,5}$. Group $2 \mathrm{PH}$ is dedicated to left heart disease where the elevation in mPAP is predominantly related to passive transmission of high left atrial pressure (i.e. post-capillary $\mathrm{PH}$ ), although pulmonary arterial remodelling may develop as a consequence of long-standing pulmonary venous hypertension ${ }^{6}$. Group $3 \mathrm{PH}$ comprises chronic lung diseases, sleep disordered breathing, alveolar hypoventilation syndromes, and chronic exposure to altitude. Group $4 \mathrm{PH}$ is related to chronic thromboembolic disease, where persisting obstruction of pulmonary arteries

\begin{tabular}{|c|c|}
\hline Group 1 & $\begin{array}{l}\text { Pulmonary arterial hypertension } \\
\text { - Idiopathic } \\
\text { - Heritable (BMPR2, ALK-1, ENG, SMAD9, CAV1, } \\
\text { KCNK3) } \\
\text { - Drug and toxin induced } \\
\text { - Associated with: connective tissue disease, HIV, } \\
\text { portal hypertension, congenital heart disease, } \\
\text { schistosomiasis }\end{array}$ \\
\hline Group 1' & $\begin{array}{l}\text { Pulmonary veno-occlusive disease and/or pulmonary } \\
\text { capillary haemangiomatosis }\end{array}$ \\
\hline Group 1" & Persistent pulmonary hypertension of the new-born \\
\hline Group 2 & Pulmonary hypertension due to left heart disease \\
\hline Group 3 & $\begin{array}{l}\text { Pulmonary hypertension due to lung diseases and/or } \\
\text { hypoxia }\end{array}$ \\
\hline Group 4 & Chronic thromboembolic pulmonary hypertension \\
\hline Group 5 & $\begin{array}{l}\text { Pulmonary hypertension with unclear and/or } \\
\text { multifactorial mechanisms }\end{array}$ \\
\hline
\end{tabular}

occurs due to non-resolution and organization of chronic thrombi. Finally, Group 5 PH consists of miscellaneous conditions with unclear or multifactorial mechanisms leading to $\mathrm{PH}$.

This review will aim to provide a succinct but comprehensive update on the therapeutic approach to $\mathrm{PH}$. For the purpose this review, we will focus on Group 1 PAH and Group 4 chronic thromboembolic pulmonary hypertension (CTEPH), since major developments have occurred recently in the management of these conditions.

\section{PULMONARY ARTERIAL HYPERTENSION}

Pulmonary arterial hypertension is characterised by proliferative and fibrotic remodelling of the distal pulmonary arteries, resulting in 
vascular luminal obstruction and a progressive rise in pulmonary vascular resistance $(\mathrm{PVR})^{7,8}$. It remains a potentially fatal disease, with right ventricular failure being the main cause of death ${ }^{9}$, but targeted medical therapy in the current era has led to significant improvements in survival $^{10-12}$. Pulmonary arterial hypertension is termed idiopathic when no aetiological factors are identified, but can also be heritable, drug and toxin-induced, or be associated with conditions such as connective tissue disease, congenital heart disease, HIV infection, and portal hypertension ${ }^{13}$. The diagnosis of PAH requires invasive haemodynamic confirmation of precapillary $\mathrm{PH}(\mathrm{mPAP} \geq 25 \mathrm{mmHg}$, PAWP $\leq 15 \mathrm{mmHg}$, and PVR $>3$ Wood units) with the exclusion of left heart disease, lung disease, and chronic thromboembolism.

Dysfunction of the endothelium is a key process in the pathogenesis of $\mathrm{PAH}$, although our current understanding suggests that the pathobiology is complex and involves predisposing factors such as inflammation and immune dysregulation, altered cross-talk between cells within the vascular wall, metabolic and mitochondrial abnormalities, abnormal growth factor stimulation and cell signalling, ion channel defects, and germline mutations ${ }^{4,14-20}$.

Until recently, agents approved for the treatment of PAH all belong to the following major therapeutic classes, which target three major molecular pathways involved in PAH pathogenesis: the prostanoids (prostacyclin pathway), endothelin-1 receptor antagonists (endothelin-1 pathway), and phosphodiesterase type 5 inhibitors (nitric oxide pathway). An additional class of agent targeting the nitric oxide pathway became available with the approval of riociguat, a soluble guanylate cyclase stimulator. All three major molecular pathways regulate pulmonary vasomotor tone and are also involved (to a variable extent) in the control of vascular cell proliferation. In PAH, there is enhanced pulmonary vasoconstriction with smooth muscle hyperplasia and a pro-proliferative, anti-apoptotic phenotype of endothelial cells ${ }^{14,21}$.

\section{Current approach to management of pulmonary arterial hypertension}

General measures include correction of hypoxaemia with supplemental oxygen, diuretics for control of volume status, exercise rehabilitation, avoidance of pregnancy in women of childbearing age, and psychological support $^{1}$. Anticoagulation should be considered for patients with idiopathic, heritable, or drug-induced PAH, although evidence supporting this practice is derived mainly from retrospective studies or single-centre experience ${ }^{22,23}$. However, a recent analysis of the large US Registry to Evaluate Early and Long-Term Disease Management in PAH (REVEAL) did not demonstrate any survival benefit for patients with idiopathic PAH who were initiated on warfarin ${ }^{24}$. The role of anticoagulation for other forms of PAH is even less clear ${ }^{24,25}$, particularly in the setting of systemic sclerosis where increased risk of gastrointestinal bleeding requires careful consideration.

The approach to PAH therapy has undergone significant evolution since intravenous epoprostenol was first approved by the FDA in 1997. Table 2 summarises the different PAH agents according to their mechanism of action. With different classes of agents becoming available, there has been a major shift away from the sole use of monotherapy towards combination 
TABle 2. Pulmonary arterial hypertension agents and their therapeutic targets

\begin{tabular}{|c|c|}
\hline Therapeutic target & Agents \\
\hline Prostacyclin pathway & $\begin{array}{l}\text { Prostanoids } \\
\text { - Epoprostenol (continuous IV infusion) } \\
\text { - Treprostinil (continuous SC/IV infusion, } \\
\text { oral or inhaled) } \\
\text { - Iloprost (inhaled) } \\
\text { - Beraprost (oral) } \\
\text { Selective IP receptor agonist } \\
\text { - Selexipag (oral) }{ }^{\dagger, t}\end{array}$ \\
\hline $\begin{array}{l}\text { Endothelin-1 pathway } \\
\text { (oral) }\end{array}$ & $\begin{array}{l}\text { Dual endothelin receptor antagonists } \\
\text { - Bosentan } \\
\text { - Macitentan } \\
\text { Selective endothelin type A receptor } \\
\text { antagonists } \\
\text { - Ambrisentan }\end{array}$ \\
\hline $\begin{array}{l}\text { Nitric oxide pathway } \\
\text { (oral) }\end{array}$ & $\begin{array}{l}\text { Phosphodiesterase type } 5 \text { inhibitors } \\
\text { - Sildenafil } \\
\text { - Tadalafil } \\
\text { - Vardenafil } \\
\text { Soluble guanylate cyclase stimulators } \\
\text { - Riociguat }\end{array}$ \\
\hline \multicolumn{2}{|c|}{$\begin{array}{l}\text { *IV treprostinil should only be used if the SC route is not tolerated. } \\
\text { Inhaled treprostinil not approved by European Medicine Agency (EMA) } \\
\text { at time of writing. } \\
\text { 'Not approved by the EMA at time of writing. } \\
\text { 'Submitted to regulatory authorities for approval. } \\
\text { IP receptor: prostacyclin I receptor; IV: intravenous; SC: subcutaneous. }\end{array}$} \\
\hline
\end{tabular}

therapy. The concept of combination therapy targeting multiple pathways simultaneously has been explored successfully in other areas such as congestive cardiac failure and cancer therapeutics. In addition, it is likely that individual PAH patients may display variations in their response to specific agents. Therefore, the use of combination therapy may increase the likelihood of an individual patient receiving an agent that he or she will respond to $^{26}$. At present, treatment response to specific agents (or classes of agents) cannot be predicted by individual patient characteristics.

Traditionally, combination therapy has been administered in a sequential manner where a second (or third) class of agent is added on top of background therapy if treatment response is inadequate ${ }^{27,28}$. Increasingly, upfront combination therapy is being utilised at the time of diagnosis, with the aim of achieving and maintaining maximal therapeutic response from the start $t^{4}$. The aggressive use of upfront combination therapy is particularly appealing in $\mathrm{PAH}$ patients who present with severe disease with unfavourable prognostic features.

\section{Algorithm of targeted pulmonary arterial hypertension therapy}

The 2015 European Society of Cardiology/European Respiratory Society (ESC/ERS) guidelines on the diagnosis and treatment of $\mathrm{PH}^{1}$ were recently published. The current guidelines recommend individualised risk stratification at the time of diagnosis to determine the initial approach to therapy.

Risk assessment aims to stratify the patient into low, intermediate, or high-risk categories according to clinical parameters that are known be predictive of prognosis ${ }^{1}$. As a multi-dimensional approach is likely to provide a more accurate assessment of risk, a panel of parameters that incorporate measures of functional capacity, right ventricular function, and pulmonary haemodynamics should be used to stratify patients into an estimated risk category. Broadly speaking, a high-risk patient corresponds to advanced World Health Organization (WHO) Functional Class (FC) III-IV with severe haemodynamics, poor exercise capacity, and impaired right ventricular function with associated clinical signs of right heart failure. Conversely, a low-risk patient is in FC I-II with good exercise capacity and preserved 
TABLE 3. Risk assessment in pulmonary arterial hypertension

\begin{tabular}{|c|c|c|c|}
\hline Prognostic marker & Low risk & Intermediate risk & High risk \\
\hline WHO FC & $|-I|$ & III & IV \\
\hline Symptoms & No progression & Slowly progressive & Rapidly progressive \\
\hline Syncope & Absent & Occasional & Recurrent \\
\hline Signs of right heart failure & Absent & Absent & Present \\
\hline 6-MWD & $>440 \mathrm{~m}^{*}$ & $165-440 \mathrm{~m}$ & $<165 \mathrm{~m}$ \\
\hline Cardiopulmonary exercise testing & $\begin{array}{l}\text { Peak VO } \mathrm{V}_{2}>15 \mathrm{ml} / \mathrm{min} / \mathrm{kg} \& \mathrm{EqCO}_{2} \\
\quad<36 \mathrm{l} / \mathrm{min} / \mathrm{l} / \mathrm{min}\end{array}$ & $\begin{array}{l}\text { Peak } \mathrm{VO}_{2} 11-15 \mathrm{ml} / \mathrm{min} / \mathrm{kg} \text { and } \\
\mathrm{EqCO}_{2} 36.0-44.9 \mathrm{l} / \mathrm{min} / \mathrm{l} / \mathrm{min}\end{array}$ & $\begin{array}{l}\text { Peak } \mathrm{VO}_{2}<11 \mathrm{ml} / \mathrm{min} / \mathrm{kg} \\
\mathrm{EqCO}_{2} \geq 45 \mathrm{I} / \mathrm{min} / \mathrm{l} / \mathrm{min}\end{array}$ \\
\hline BNP/NT-proBNP & Normal & Moderately elevated & Markedly elevated \\
\hline Echocardiography/CMRI & $\mathrm{RA}<18 \mathrm{~cm}^{2}$ & $\mathrm{RA} 18-26 \mathrm{~cm}^{2}$ & $\begin{array}{l}\mathrm{RA}>26 \mathrm{~cm}^{2} \\
\text { Pericardial effusion }\end{array}$ \\
\hline Haemodynamics & $\begin{array}{l}\mathrm{RAP}<8 \mathrm{mmHg} \\
\mathrm{Cl} \geq 2.5 \mathrm{I} / \mathrm{min} / \mathrm{m}^{2}\end{array}$ & $\begin{array}{l}\text { RAP 8-14 } \mathrm{mmHg} \\
\mathrm{CI} 2.0-2.4 \mathrm{l} / \mathrm{min} / \mathrm{m}^{2}\end{array}$ & $\begin{array}{l}\mathrm{RAP}>14 \mathrm{mmHg} \\
\mathrm{Cl}<2.0 \mathrm{l} / \mathrm{min} / \mathrm{m}^{2}\end{array}$ \\
\hline Estimated 1-year mortality & $<5 \%$ & $5-10 \%$ & $>10 \%$ \\
\hline
\end{tabular}

*For younger individuals, a higher target would be expected.

Cl: cardiac index; CMRI: cardiac magnetic resonance imaging; $\mathrm{EqCO}_{2}$ : ventilatory equivalent for carbon dioxide; NT-proBNP: N-terminal pro-brain natriuretic protein; RA: right atrium; RAP: right atrial pressure; 6-MWD: six-minute walk distance; $\mathrm{VO}_{2}$ : oxygen consumption; WHO FC: World Health Organization functional class.

Reproduced with permission from the 2015 ESC/ERS guidelines for the diagnosis and treatment of $\mathrm{PH}^{\text {? }}$.

right ventricular function. Table 3 provides the current ESC/ERS recommendations on risk assessment in PAH.

Patients with high-risk features should be offered aggressive upfront combination therapy at the time of diagnosis, and one of the agents included should be intravenous epoprostenol $^{1}$. Despite the complexities of continuous intravenous therapy, epoprostenol remains the only agent that has demonstrated a survival benefit over three months in high-risk patients ${ }^{29}$. Thus, intravenous epoprostenol should be viewed as the cornerstone of PAH therapy in those with severe, high-risk disease. Recently, Sitbon et al. ${ }^{30}$ showed major functional and haemodynamic improvements in a group of high-risk patients with idiopathic, heritable, or anorexigen-induced $\mathrm{PAH}$ who were initiated on upfront triple therapy with intravenous epoprostenol, bosentan, and sildenafil. Patients were in FC III-IV at presentation, with severe haemodynamic impairment (defined as $<2.01 \cdot \mathrm{min}^{-1} \cdot \mathrm{m}^{-2}$ and/or mean right atrial pressure $>20 \mathrm{mmHg}$ and/ or PVR $\geq 1000$ dyn $\cdot \mathrm{s} \cdot \mathrm{cm}^{-5}$ ). At an average follow-up of $32.3 \pm 19.4$ months, 17 of 19 patients were maintained in FC I-II, six-minute walk distance (6-MWD) improved from a baseline of $227 \pm 171$ to $514 \pm 105 \mathrm{~m}(\mathrm{p}<0.01)$, and survival was $100 \%$ with only one patient requiring lung transplantation. Although this series was small and observational in nature, it provides support for the strategy of combining intravenous epoprostenol with oral agents as initial therapy for high-risk PAH.

For patients with low- or intermediate-risk features at diagnosis, the recent AMBITION study $^{31}$ (AMBrIsentan and Tadalafil in patients with pulmonary arterial hypertensION) has provided high-quality evidence in support 
of an upfront strategy of oral combination therapy. AMBITION was a multicentre, longterm, morbidity and mortality event-driven RCT that evaluated the initial combination of ambrisentan and tadalafil versus ambrisentan or tadalafil alone in FC II-III patients. In the primary analysis set of 500 patients, upfront combination therapy was associated with a $50 \%$ reduction in the risk of the primary endpoint of the first event of clinical failure, compared to the pooled monotherapy arms (HR: 0.50; 95\% CI: 0.35-0.72; p < 0.001). Clinical failure was defined by a composite of death, hospitalisation for worsening PAH, disease progression, or unsatisfactory longterm clinical response. The primary endpoint was largely driven by a reduction in hospitalisations for PAH. Secondary outcomes such as 6-MWD, N-terminal-pro-brain natriuretic peptide (NT-proBNP), and proportion of patients with satisfactory clinical response were also in favour of the combination therapy arm. Treatment effect was consistent across different subgroups according to disease aetiology, FC, age, sex, and baseline 6-MWD. Accordingly, the 2015 ESC/ERS guidelines ${ }^{1}$ have provided a recommendation that either an upfront oral combination therapy or oral monotherapy should be used for low- to intermediate-risk patients at diagnosis.

An important aspect of the current approach to PAH therapy is that patients should be monitored closely with early assessment (3-4 months) of treatment response following initiation of first-line therapy, regardless of whether an upfront monotherapy or combination therapy strategy is adopted. The goal of therapy is to achieve and maintain a lowrisk profile, according to the risk assessment described above (Table 3$)^{1}$. Sequential addition of therapy (with a second or third class of agent) should be instituted if treatment response is deemed to be unsatisfactory at follow-up. Although the best timing for lung transplantation referral is still debated, it is reasonable that eligible patients should be referred early if adequate treatment response is not achieved. Figure 1 describes the current evidence-based PAH treatment algorithm adapted from the 2015 ESC/ERS guidelines.

\section{Combination therapy: The evidence for different drug combinations}

An accumulating number of RCTs have now been performed evaluating different combinations of targeted PAH agents. Recent meta-analyses support the efficacy of combination therapy in improving clinical outcomes but with uncertain effect on mortality ${ }^{32,33}$. At present, no head-to-head trials have been conducted that compare the efficacy of different combinations of PAH agents. Thus, direct comparative data are not available to inform the superiority of one specific drug combination over another. Furthermore, the clinical decision on how to combine different PAH agents may be influenced by variations in access to targeted medical therapy worldwide. Table 4 summarises the characteristics and results of the major combination therapy RCTs in PAH.

In terms of upfront combination therapy, only two RCTs have been published to date. As discussed earlier, the AMBITION study ${ }^{31}$ demonstrated that the combination of ambrisentan and tadalafil was superior to monotherapy alone in the first event of clinical failure. Although treatment was well tolerated in general, 


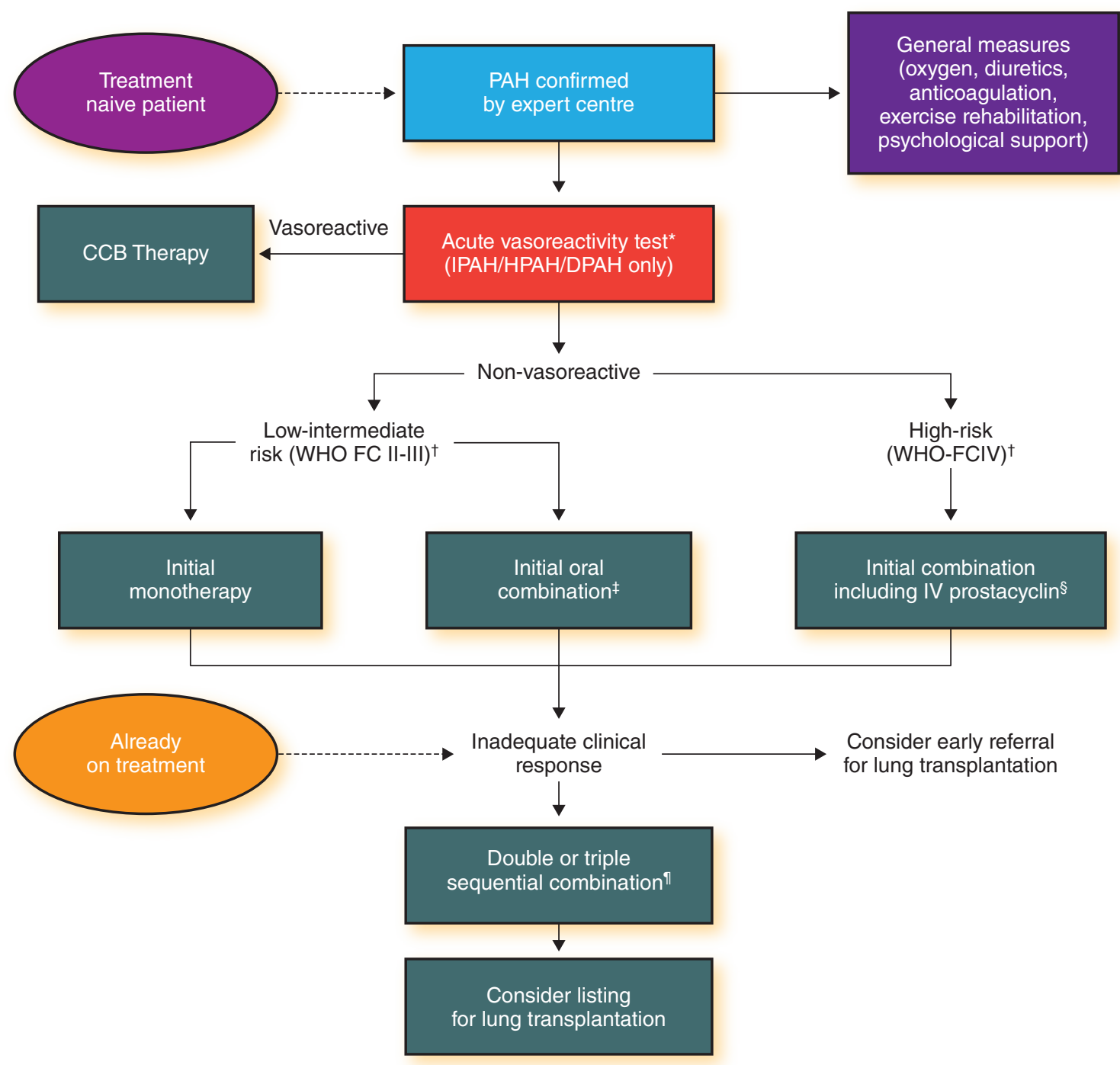

Figure 1. Evidence-based treatment algorithm for Group 1 pulmonary arterial hypertension patients (reproduced with permission from the 2015 ESC/ERS Guidelines for the diagnosis and treatment of $\mathrm{PH}^{1}$ ).

${ }^{*}$ Positive acute vasoreactivity is defined by a reduction of mPAP of $>10 \mathrm{mmHg}$ to an absolute level of $<40 \mathrm{mmHg}$ together with increased or unchanged cardiac output. Acute vasoreactivity can be performed with inhaled nitric oxide, intravenous adenosine, or intravenous epoprostenol.

${ }^{\dagger}$ Some WHO-FC III patients may be considered high-risk (Table 3).

IInitial combination with ambrisentan and tadalafil has proven to be superior to initial monotherapy with either ambrisentan or tadalafil in delaying clinical failure.

§Intravenous epoprostenol should be prioritised as it has reduced the three months rate for mortality in high-risk PAH patients also as monotherapy.

"Combine agents acting on different pathomechanistic pathways (Table 2).

CCB: calcium channel blocker; DPAH: drug- and toxin-associated PAH; HPAH: hereditary PAH; IPAH: idiopathic PAH;

IV PCA: intravenous prostacyclin; PAH: pulmonary arterial hypertension; WHO-FC: World Health Organisation Functional Class. 
TABLE 4. Characteristics and results of major phase III randomized controlled trials of combination therapy in pulmonary arterial hypertension

\begin{tabular}{|c|c|c|c|c|c|c|c|}
\hline Drug tested & Background therapy (\%) & $\begin{array}{l}\text { No. of } \\
\text { subjects } \\
\text { (trial total) }\end{array}$ & Duration & Primary endpoint & $\begin{array}{l}\text { Primary } \\
\text { endpoint } \\
\text { met? }\end{array}$ & Comment & Ref \\
\hline $\begin{array}{l}\text { Sequential inhaled } \\
\text { iloprost (STEP) }\end{array}$ & Bosentan & 67 & 12 weeks & 6-MWD & No & $\begin{array}{l}\text { Primary endpoint did not meet defined statistical } \\
\text { significance }(p=0.051) \text {. Improvement in } \\
\text { TTCW, FC, and haemodynamics. }\end{array}$ & 70 \\
\hline $\begin{array}{l}\text { Sequential inhaled } \\
\text { iloprost (COMBI) }\end{array}$ & Bosentan & 40 & 12 weeks & 6-MWD & No & $\begin{array}{l}\text { Trial was stopped early after interim analysis } \\
\text { revealed low likelihood of reaching primary } \\
\text { endpoint. }\end{array}$ & 71 \\
\hline $\begin{array}{l}\text { Sequential inhaled } \\
\text { treprostinil } \\
\text { (TRIUMPH-1) }\end{array}$ & $\begin{array}{l}\text { Bosentan }(70 \%) \\
\text { Sildenafil }(30 \%)\end{array}$ & 235 & 12 weeks & 6-MWD & Yes & $\begin{array}{l}\text { No difference in TTCW but QoL improved in } \\
\text { treprostinil group. }\end{array}$ & 72 \\
\hline $\begin{array}{l}\text { Sequential oral } \\
\text { treprostinil } \\
\text { (FREEDOM-C) }\end{array}$ & $\begin{array}{l}\text { ERA }(30 \%) \\
\text { PDE5i }(25 \%) \\
\text { ERA + PDE5i }(45 \%)\end{array}$ & 350 & 16 weeks & 6-MWD & No & No difference in TTCW. & 73 \\
\hline $\begin{array}{l}\text { Sequential oral } \\
\text { treprostinil } \\
\text { (FREEDOM-C2) }\end{array}$ & $\begin{array}{l}\text { ERA }(17 \%) \\
\text { PDE5i (43\%) } \\
\text { ERA + PDE5i (40\%) }\end{array}$ & 310 & 16 weeks & 6-MWD & No & $\begin{array}{l}\text { No significant differences in all secondary } \\
\text { endpoints including TTCW. }\end{array}$ & 74 \\
\hline $\begin{array}{l}\text { Sequential tadalafil } \\
\text { (PHIRST) }\end{array}$ & $\begin{array}{l}\text { Bosentan }(53 \%) \\
\text { Nil }(47 \%)\end{array}$ & 405 & 16 weeks & 6-MWD & Yes* & $\begin{array}{l}\text { Primary endpoint was met for entire study cohort, } \\
\text { but subgroup on background therapy did not } \\
\text { demonstrate improvement in 6-MWD or FC. }\end{array}$ & 75 \\
\hline $\begin{array}{l}\text { Sequential } \\
\text { sildenafil } \\
\text { (PACES) }\end{array}$ & Epoprostenol & 267 & 16 weeks & 6-MWD & Yes & $\begin{array}{l}\text { Significantly delayed TTCW with improvement in } \\
\text { haemodynamics and } \mathrm{OoL} \text {. }\end{array}$ & 35 \\
\hline $\begin{array}{l}\text { Sequential } \\
\text { macitentan } \\
\text { (SERAPHIN) }\end{array}$ & $\begin{array}{l}\text { Oral/inhaled prostanoid }(5 \%) \\
\text { PDE5i }(61 \%) \\
\text { Nil }(34 \%)\end{array}$ & 742 & $\begin{array}{l}\text { Median } \\
\text { exposure } \\
115 \text { weeks }\end{array}$ & $\begin{array}{l}\text { Composite } \\
\text { morbidity/mortality } \\
\text { event }\end{array}$ & Yes & $\begin{array}{l}\text { Primary endpoint met with } 45 \% \text { reduction in } \\
\text { morbidity/mortality event, mainly driven by } \\
\text { reduction in PAH worsening. Efficacy } \\
\text { demonstrated in pre-specified subgroup on } \\
\text { background therapy. }\end{array}$ & 36 \\
\hline $\begin{array}{l}\text { Sequential } \\
\text { riociguat } \\
\text { (PATENT-1) }\end{array}$ & $\begin{array}{l}\text { ERA }(44 \%) \text { Oral/inhaled } \\
\text { prostanoid }(6 \%) \\
\text { Nil }(50 \%)\end{array}$ & 443 & 12 weeks & 6-MWD & Yes & $\begin{array}{l}\text { Efficacy demonstrated in pre-specified subgroup } \\
\text { on background therapy. Improved TTCW, FC } \\
\text { and PVR. }\end{array}$ & 37 \\
\hline $\begin{array}{l}\text { Sequential } \\
\text { bosentan } \\
\text { (COMPASS-2) }\end{array}$ & Sildenafil & 334 & $\begin{array}{l}\text { Mean } \\
\text { exposure } \\
26 \text { months }\end{array}$ & $\begin{array}{l}\text { Composite } \\
\text { morbidity/mortality } \\
\text { event-driven } \\
\text { endpoint }\end{array}$ & No & $\begin{array}{l}\text { Small but significant improvement 6-MWD and } \\
\text { NT-proBNP. }\end{array}$ & 39 \\
\hline $\begin{array}{l}\text { Sequential } \\
\text { selexipag } \\
\text { (GRIPHON) }\end{array}$ & $\begin{array}{l}\text { ERA or PDE5i }(47 \%) \\
\text { ERA + PDE5i }(33 \%) \\
\text { Nil }(20 \%)\end{array}$ & 1,156 & $\begin{array}{l}\text { Mean } \\
\text { exposure } \\
76 \text { weeks }\end{array}$ & $\begin{array}{l}\text { Composite } \\
\text { morbidity/mortality } \\
\text { event-driven } \\
\text { endpoint }\end{array}$ & Yes & $\begin{array}{l}\text { Primary endpoint was met with } 40 \% \text { reduction in } \\
\text { morbidity/mortality events in active group. } \\
\text { Efficacy appeared consistent across subgroups } \\
\text { including those on background dual therapy. }\end{array}$ & 43 \\
\hline $\begin{array}{l}\text { Upfront } \\
\text { epoprostenol + } \\
\text { bosentan } \\
\text { (BREATHE-2) }\end{array}$ & All treatment-naive & 33 & 16 weeks & PVR & No & $\begin{array}{l}\text { Trend (non-significant) towards improved } \\
\text { haemodynamics. } \\
\text { No significant change in secondary endpoints. }\end{array}$ & 34 \\
\hline $\begin{array}{l}\text { Upfront } \\
\text { ambrisentan + } \\
\text { tadalafil } \\
\text { (AMBITION) }\end{array}$ & All treatment-naive & 500 & $\begin{array}{l}\text { Mean } \\
\text { exposure } \\
517 \text { days }\end{array}$ & $\begin{array}{l}\text { Composite } \\
\text { morbidity/mortality } \\
\text { event-driven } \\
\text { endpoint }\end{array}$ & Yes & $\begin{array}{l}\text { Primary endpoint met with } 50 \% \text { reduction in } \\
\text { morbidity/mortality events for the combination } \\
\text { arm, mainly due to reduction in PAH } \\
\text { hospitalisation. Significant improvements in } \\
6 \text {-MWD, NT-proBNP, and satisfactory clinical } \\
\text { response. Anaemia, peripheral oedema, } \\
\text { headache occurred more frequently in } \\
\text { combination therapy group. }\end{array}$ & 31 \\
\hline
\end{tabular}

*Primary endpoint was met for the entire study cohort, but not for the subgroup on background PAH therapy.

APAH: associated pulmonary arterial hypertension; ERA: endothelin receptor antagonist; FC: functional class; IPAH: idiopathic pulmonary arterial hypertension;

LTE: long-term extension; NT-proBNP: N-terminal pro-brain natriuretic peptide; PAH: pulmonary arterial hypertension; PAH-CTD: PAH secondary to connective tissue disease; PDE5i: PDE5 inhibitor; PVR: pulmonary vascular resistance; QoL: quality of life; SBP: systolic blood pressure; 6-MWD: six-minute walk distance; TPR: total pulmonary resistance; TTCW: time to clinical worsening; for randomised controlled trial acronyms, see text. 
adverse events that occurred more frequently in the ambrisentan/tadalafil combination group included peripheral oedema, headache, nasal congestion, and anaemia. BREATHE-2 ${ }^{34}$ was a small study of $33 \mathrm{PAH}$ patients who were randomised to upfront combination therapy with epoprostenol plus bosentan or epoprostenol alone. The primary endpoint of haemodynamic improvement was not met, although there was a trend towards a greater reduction in PVR in the combination therapy group. No significant differences in FC or 6-MWD were observed, although this study was not powered to address these clinical endpoints.

A larger number of RCTs are available with regards to sequential combination therapy in PAH. However, results have been mixed, with some trials failing to meet their primary endpoint (Table 4).

The PACES trial ${ }^{35}$ (Pulmonary Arterial hypertension Combination study of Epoprostenol and Sildenafil) evaluated the addition of sildenafil to background intravenous epoprostenol therapy. After 16 weeks of treatment, improvements were seen in haemodynamics, 6-MWD, and time to clinical worsening compared with placebo. However, the sequence of adding sildenafil on top of background intravenous epoprostenol therapy is not commonly employed in clinical practice, particularly in view of the current recommendation that high-risk patients should be initiated on upfront combination therapy with intravenous epoprostenol being one of the agents.

The addition of macitentan to background PAH therapy in the SERAPHIN trial (Study with an Endothelin Receptor Antagonist in Pulmonary arterial Hypertension to Improve
cliNical outcome) was demonstrated to be effective in a long-term morbidity/mortality event-driven study ${ }^{36}$. In this study, a total of 742 patients were randomised to macitentan versus placebo, with 454 patients on existing phosphodiesterase type 5 (PDE-5) inhibitor and 40 patients on non-parenteral prostanoid therapies. Macitentan at $10 \mathrm{mg}$ was associated with a reduction in hazard ratio versus placebo of 0.55 (97.5\% CI: 0.39-0.76; $\mathrm{p}=<0.001)$ for the primary composite morbidity/mortality endpoint, which was mainly driven by worsening of PAH.

Riociguat is a soluble guanylate cyclase stimulator acting on the nitric oxide pathway, and is efficacious when combined with endothelin-1 receptor antagonists (ERA) and non-parenteral prostanoids (PATENT-1: Pulmonary Arterial hyperTENsion sGC-stimulator Trial-1 ${ }^{37}$. The traditional endpoint of 6-MWD was used in this RCT and 222 of 443 patients were on background therapy with predominantly ERAs $(n=194)$. Addition of riociguat to background therapy at 12 weeks led to significant improvements in 6-MWD, PVR, NT-proBNP, FC, and time to clinical worsening.

The combination of riociguat added to PDE5 inhibitors is contraindicated. In the small PATENT-PLUS study ${ }^{38}(\mathrm{n}=18)$, combination therapy (riociguat added to sildenafil) demonstrated no beneficial effects at 12 weeks in terms of haemodyamics and 6-MWD. The primary outcome was a safety endpoint of supine systolic blood pressure, which did not show any difference between riociguat and placebo. In the long-term open-label extension study, the combination of riociguat and sildenafil was associated with unfavourable safety signals, with high rates of 
discontinuation due to hypotension and adverse events.

Despite the widespread use of the bosentan and sildenafil combination, the efficacy of this combination has not been proven in the setting of RCTs. The COMPASS- 2 study ${ }^{39}$ was a phase IV RCT, which evaluated the addition of bosentan to patients on background sildenafil therapy. Overall, 334 patients were randomised to bosentan or placebo and the composite primary endpoint of time to the first morbidity/mortality event was not met (defined as death, hospitalisation for PAH worsening or intravenous prostanoid initiation, atrial septostomy, lung transplant, or worsening PAH). However, significant improvements were seen in the secondary endpoints of 6-MWD and NT-proBNP. A smaller study that evaluated the opposite approach of adding sildenafil to background bosentan therapy did not meet its primary endpoint of 6-MWD $(\mathrm{NCT} 00323297)^{40}$.

\section{Upcoming therapies in pulmonary arterial hypertension}

Selexipag is a highly selective agonist of the IP receptor, the main target of the prostacyclin pathway ${ }^{41,42}$. It is a novel agent that is given orally and is distinct in terms of its molecular structure from currently approved prostacyclin derivatives. Selexipag was recently tested in the largest RCT in PAH to date (GRIPHON trial: Prostacyclin (PGI2) Receptor agonist In Pulmonary arterial HypertensiON $)^{43}$, which enrolled 1,156 patients with PAH. The majority of patients $(80 \%)$ were on background therapy with either endothelin receptor antagonist (ERA) or PDE-5 inhibitor monotherapy (47\%), or ERA plus PDE-5 inhibitor dual combination therapy (33\%). Importantly, GRIPHON represents the first trial where a substantial subgroup was on dual background therapy. The primary endpoint of time to first morbidity and mortality event was met for the overall study population, with hazard ratio of 0.60 (99\% CI: $0.46-0.78$; $\mathrm{p}<0.0001)$ favouring selexipag-treated patients compared to placebo. Comparable benefits were also shown in those on dual background therapy. Selexipag appeared to be well tolerated and no new safety concerns were noted over the long-term administration of treatment.

\section{CHRONIC THROMBOEMBOLIC PULMONARY HYPERTENSION}

Chronic thromboembolic pulmonary hypertension (CTEPH) is a distinct subgroup of precapillary pulmonary hypertension caused by persisting obstruction of the pulmonary arteries after pulmonary embolism despite three months of correct therapeutic anticoagulation ${ }^{44}$. Approximately $75 \%$ of patients will have antecedent symptomatic pulmonary embolism, but a significant proportion will not have a clear history ${ }^{45}$. CTEPH is likely to be under-diagnosed, and the true incidence and prevalence of the condition is uncertain. In recent studies which utilised right heart catheter for diagnosis, prevalence after acute pulmonary embolism has been estimated at $0.4-4.8 \%$ before two years ${ }^{46-49}$.

The pathogenesis of CTEPH involves defective thrombus resolution with maladaptive vascular remodelling, leading to formation of organised fibrotic tissue and intraluminal webs and bands, 
which cause obstruction in the major pulmonary arteries ${ }^{50}$. Large vessel occlusion can be accompanied by a small vessel arteriopathy that is histologically similar to $\mathrm{PAH}^{51}$. This microvascular disease can be demonstrated in small vessels distal to both obstructed and non-obstructed elastic pulmonary arteries.

Chronic thromboembolic pulmonary hypertension is usually suspected by the presence of mismatched perfusion defects on ventilation-perfusion scintigraphy, which remains the most sensitive initial screening test ${ }^{52}$. The diagnosis of CTEPH is confirmed by subsequent demonstration of obstruction of the pulmonary arteries on imaging modalities such as conventional digital subtraction pulmonary angiography or computed tomography pulmonary angiography. Invasive haemodynamic testing is required to confirm the presence of precapillary PH. Lifelong anticoagulation (usually with warfarin) is mandatory for patients with CTEPH and data is currently lacking to support the use of novel oral anticoagulants in this population ${ }^{53,54}$.

\section{Surgical therapy}

Pulmonary endarterectomy (PEA) remains the treatment of choice for CTEPH and is potentially curative. At high-volume centres, surgical results have improved substantially over time. Periprocedural mortality is $<5 \%$ due to greater surgical experience, improved patient selection, and postoperative care ${ }^{55,56}$. A multidisciplinary assessment of operability at a PEA centre by PH physicians, surgeons, and radiologists is mandatory since not all patients are deemed to be suitable for PEA based on the site of disease or severe medical comorbidities $^{1,44}$. The assessment of operability remains subjective and is largely dependent on the experience and surgical expertise of the centre. Thus, referral for a second opinion should be considered if the decision regarding operability is not straightforward ${ }^{44}$. Some patients will have predominantly distal disease that is regarded as technically inaccessible by the surgeon, or the burden of surgically accessible disease is inadequate to explain the severity of haemodynamic impairment, suggesting the presence of a major component of distal disease. Age in itself is not a contraindication, and there is no PVR threshold or degree of right ventricular dysfunction that necessarily precludes PEA ${ }^{55}$.

Warranting mention is the subset of patients with symptomatic chronic thromboembolic disease without resting $\mathrm{PH}$. The approach to these patients is not standardised, but given the potential for progression of disease, PEA should be considered, especially in those who demonstrate abnormal cardiopulmonary response during exercise. A recent case series of PEA in 42 patients with chronic thromboembolic disease and $\mathrm{mPAP}<25 \mathrm{mmHg}$ demonstrated beneficial effects with improvements in exercise capacity and quality of life $\mathrm{f}^{57}$.

According to European CTEPH registry data collected from 2007-2009, 37\% of CTEPH patients were classified as inoperable, and $16.7 \%$ had persistent pulmonary hypertension postoperatively ${ }^{58}$. Patients should have comprehensive clinical re-evaluation following surgery to determine the haemodynamic result and whether significant persistent pulmonary hypertension is present. Regardless of surgical outcome, life-long anticoagulation must be continued. 
TABLE 5. Summary of randomised controlled trials of targeted medical therapy for inoperable/ persistent/recurrent chronic thromboembolic pulmonary hypertension

\begin{tabular}{|l|c|l|l|l|l|l|}
\hline $\begin{array}{l}\text { Drug } \\
\text { tested }\end{array}$ & $\begin{array}{c}\text { Subjects } \\
(\mathbf{n})\end{array}$ & $\begin{array}{l}\text { Characteristics } \\
\text { of subjects }\end{array}$ & Duration & $\begin{array}{l}\text { Primary } \\
\text { endpoint }\end{array}$ & $\begin{array}{c}\text { Primary } \\
\text { endpoint met? }\end{array}$ & Comment \\
\hline $\begin{array}{l}\text { Riociguat } \\
\text { (CHEST-1) }\end{array}$ & 261 & $\begin{array}{c}\text { Postoperative } \\
(27 \%)\end{array}$ & 16 weeks & 6-MWD & Yes & $\begin{array}{l}\text { Ref } \\
\text { Independent adjudication panel } \\
\text { confirmed inoperability. Primary } \\
\text { endpoint met, and improvements in } \\
\text { PVR, NT-proBNP, FC, Borg and QoL. } \\
\text { Generally well tolerated, haemop- } \\
\text { tysis in 2\% of treatment group. }\end{array}$ \\
\hline $\begin{array}{l}\text { Bosentan } \\
\text { (BENEFiT) }\end{array}$ & 157 & $\begin{array}{l}\text { Postoperative } \\
(28 \%)\end{array}$ & 16 weeks & $\begin{array}{l}\text { PVR and 6-MWD } \\
\text { (Co-primary } \\
\text { endpoints) }\end{array}$ & No & $\begin{array}{c}\text { Significant improvement in PVR (in } \\
\text { both postoperative and inoperable } \\
\text { patients) but no significant } \\
\text { difference in 6-MWD. }\end{array}$ \\
\hline Sildenafil & 19 & $\begin{array}{c}\text { Postoperative } \\
(47 \%)\end{array}$ & 12 weeks & 6-MWD & 62 \\
\hline
\end{tabular}

FC: functional class; NT-proBNP: N-terminal pro-brain natriuretic peptide; PVR: pulmonary vascular resistance; QoL: quality of life; 6-MWD: six-minute walk distance; TTCW: time to clinical worsening; for randomised controlled trial acronyms see text.

\section{Targeted medical therapy for inoperable or persistent/recurrent chronic thromboembolic pulmonary hypertension}

Given the similarities in the microvascular disease of PAH and CTEPH, targeted medical therapies have been evaluated to treat inoperable or recurrent/persistent CTEPH patients (Table 5). Riociguat is the only drug currently approved for the treatment of inoperable CTEPH or persistent/recurrent CTEPH post-surgery. In CHEST-1 (CHronic thromboEmbolic pulmonary hypertension Soluble guanylate cyclase-stimulator Trial) ${ }^{59}$, a randomized, double-blind, placebo-controlled trial conducted in 261 patients with inoperable or persistent/recurrent CTEPH, riociguat significantly improved PVR, 6-MWD, FC, and NT-proBNP after 16 weeks of treatment and was generally well-tolerated. Importantly, all patients in CHEST-1 were assessed by an independent adjudication panel for the assessment of inoperability. The CHEST- $2^{60}$ open-label extension study showed sustained benefits in
6-MWD and FC for up to one year, with no new safety signals identified.

Sildenafil has been evaluated in a small RCT involving 19 patients with inoperable CTEPH ${ }^{61}$. The primary endpoint of 6-MWD was negative, but a significant improvement in PVR was demonstrated in the sildenafil arm. The BENEFIT study (Bosentan Effects in iNopErable Forms of chronIc Thromboembolic pulmonary hypertension) ${ }^{62}$ randomised 157 patients with inoperable CTEPH or persistent/ recurrent CTEPH post-surgery to bosentan or placebo. In this study, PVR and 6-MWD were used as co-primary endpoints, and a significant improvement in PVR but not 6-MWD was demonstrated in those assigned to bosentan. On-going RCTs are being conducted to evaluate the efficacy of subcutaneous treprostinil (NCT01416636) and maciten$\tan$ (NCT02021292) for inoperable CTEPH.

Controlled data regarding preoperative treatment of CTEPH with medical therapies is lacking. The use of such "bridging" therapy prior 
to surgery in otherwise stable patients is not supported by current evidence and may delay appropriate surgery.

\section{Balloon pulmonary angioplasty}

Balloon pulmonary angioplasty (BPA) is a catheter-based technique that is garnering attention worldwide as a treatment option for inoperable CTEPH. The concept is simple and involves a balloon dilatation of occluded arteries $^{63}$. Japanese investigators have refined the BPA technique in recent years, using smaller balloons and performing staged angioplasty procedures in an attempt to reduce the incidence of reperfusion pulmonary oedema and vascular injury ${ }^{64}$. Most patients require between 3-5 staged procedures in total in order to treat as many occluded arterial segments as possible.

Currently, BPA is being offered to suitable CTEPH patients who are inoperable (or have failed PEA) and have no contraindications to angioplasty such as advanced renal insufficiency. However, as surgical assessment of operability varies according to the experience of different centres, published data on BPA outcomes have included patients who might otherwise be deemed to be operable in other centres. Nevertheless, contemporary BPA studies ${ }^{64-69}$ show consistently favourable haemodynamic effects, reporting a $33-65 \%$ reduction in PVR, and improvements in FC and 6-MWD. Dramatic responses to BPA with normalisation or near-normalisation of haemodynamics have been reported. Regarding adverse events, recent studies ${ }^{64-69}$ report serious reperfusion pulmonary oedema in $0-7 \%$ of treated patients, pulmonary artery injury in
2-7\% of patients, and periprocedural mortality of $0-10 \%$. Long-term data regarding BPA outcomes are still lacking, although experience from Japanese investigators indicate that restenosis appears to be an uncommon event.

Although it is clear that BPA will play an important role in the management of CTEPH, its exact place in the treatment algorithm is still evolving. Further studies are required to determine whether BPA should be the initial treatment approach for suitable patients with inoperable CTEPH, or whether BPA can potentially be combined with surgery or even used in place of surgery in selected patients.

\section{CONCLUSIONS}

Significant developments in the treatment options for patients with PAH and CTEPH have occurred recently. The pathobiology of PAH is complex and involves multiple molecular pathways, some of which can now be targeted by an increasing number of approved agents. The PAH agents from different classes can be combined to maximise treatment response, and an aggressive upfront combination strategy should be employed particularly in patients who present with high-risk disease. Direct comparative data regarding the efficacy of different combinations of PAH agents are currently lacking. The cornerstone of CTEPH management requires a multidisciplinary team assessment to determine whether a patient has operable disease, since PEA is a potentially curative procedure. For inoperable CTEPH, riociguat has recently been approved and there is growing evidence in support of BPA, although extensive experience with this procedure remains limited 
outside of Japan. Whilst there is regional variation in access to subsidised therapy and technical expertise, it is exciting to see that the management options and outcomes for patients with $\mathrm{PAH}$ and CTEPH are continuing to improve over time.

\section{REFERENCES}

1. Galie N, Humbert M, Vachiery JL et al. 2015 ESC/ERS Guidelines for the diagnosis and treatment of pulmonary hypertension: The Joint Task Force for the Diagnosis and Treatment of Pulmonary Hypertension of the European Society of Cardiology (ESC) and the European Respiratory Society (ERS): Endorsed by: Association for European Paediatric and Congenital Cardiology (AEPC), International Society for Heart and Lung Transplantation (ISHLT). Eur Respir J. 2015;46:903-75.

2. Hoeper MM, Bogaard HJ, Condliffe R et al. Definitions and diagnosis of pulmonary hypertension. J Am Coll Cardiol. 2013;62:D42-50.

3. Simonneau G, Gatzoulis MA, Adatia I et al. Updated clinical classification of pulmonary hypertension. J Am Coll Cardiol. 2013;62:D34-41.

4. Humbert M, Lau EM, Montani D et al. Advances in therapeutic interventions for patients with pulmonary arterial hypertension. Circulation. 2014; 130:2189-208.

5. Galie N, Manes A, Negro L et al. A meta-analysis of randomized controlled trials in pulmonary arterial hypertension. Eur Heart J. 2009;30:394-403.

6. Vachiery JL, Adir Y, Barbera JA et al. Pulmonary hypertension due to left heart diseases. J Am Coll Cardiol. 2013;62:D100-8.

7. Pietra GG, Edwards WD, Kay JM et al. Histopathology of primary pulmonary hypertension. A qualitative and quantitative study of pulmonary blood vessels from 58 patients in the National Heart, Lung, and Blood Institute, Primary Pulmonary Hypertension Registry. Circulation. 1989;80:1198-206

8. Tuder RM, Archer SL, Dorfmuller P et al. Relevant issues in the pathology and pathobiology of pulmonary hypertension. J Am Coll Cardiol. 2013;62:D4-12.

9. Tonelli AR, Arelli V, Minai OA et al. Causes and circumstances of death in pulmonary arterial hypertension. Am J Respir Crit Care Med. 2013;188:365-9.

10. Humbert M, Sitbon O, Chaouat A et al. Survival in patients with idiopathic, familial, and anorexigen-associated pulmonary arterial hypertension in the modern management era. Circulation. 2010;122:156-63.

11. Benza RL, Miller DP, Barst RJ et al. An evaluation of long-term survival from time of diagnosis in pulmonary arterial hypertension from the REVEAL Registry. Chest. 2012;142:448-56.

12. Thenappan T, Shah SJ, Rich S et al. Survival in pulmonary arterial hypertension: a reappraisal of the NIH risk stratification equation. Eur Respir J. 2010;35:1079-87.

13. Lau EM, Humbert M. A Critical Appraisal of the Updated 2014 Nice Pulmonary Hypertension Classification System. Can J Cardiol. 2015;31:367-74.

14. Morrell NW, Adnot S, Archer SL et al. Cellular and molecular basis of pulmonary arterial hypertension. J Am Coll Cardiol. 2009;54:S20-31.

15. Humbert M, Sitbon O, Simonneau G. Treatment of pulmonary arterial hypertension. N Engl J Med. 2004;351:1425-36

16. Guignabert C, Tu L, Girerd B et al. New molecular targets of pulmonary vascular remodeling in pulmonary arterial hypertension: importance of endothelial communication. Chest. 2015;147:529-37.

17. Rabinovitch M, Guignabert C, Humbert M et al. Inflammation and immunity in the pathogenesis of pulmonary arterial hypertension. Circ Res. 2014;115:165-75.

18. Guignabert C, Tu L, Le Hiress M et al. Pathogenesis of pulmonary arterial hypertension: lessons from cancer. Eur Respir Rev. 2013;22:543-51.
19. Boucherat O, Chabot S, Antigny F et al. Potassium channels in pulmonary arterial hypertension. Eur Respir J. 2015;46:1167-77.

20. Archer SL, Weir EK, Wilkins MR. Basic science of pulmonary arterial hypertension for clinicians: new concepts and experimental therapies. Circulation. 2010;121:2045-66.

21. Humbert M, Morrell NW, Archer SL et al. Cellular and molecular pathobiology of pulmonary arterial hypertension. J Am Coll Cardiol. 2004;43:13-24S.

22. Rich S, Kaufmann E, Levy PS. The effect of high doses of calcium-channel blockers on survival in primary pulmonary hypertension. N Engl J Med. 1992;327:76-81.

23. Fuster V, Steele PM, Edwards WD et al. Primary pulmonary hypertension: natural history and the importance of thrombosis. Circulation. 1984;70:580-7.

24. Preston IR, Roberts KE, Miller DP et al. Effect of warfarin treatment on survival of patients with pulmonary arterial hypertension (PAH) in the Registry to Evaluate Early and Long-Term PAH Disease Management (REVEAL). Circulation. 2015;132:2403-11.

25. Olsson KM, Delcroix M, Ghofrani HA et al. Anticoagulation and survival in pulmonary arterial hypertension: results from the Comparative, Prospective Registry of Newly Initiated Therapies for Pulmonary Hypertension (COMPERA). Circulation. 2014;129:57-65.

26. Humbert M, Ghofrani HA. The molecular targets of approved treatments for pulmonary arterial hypertension. Thorax. 2016;71:73-83.

27. Hoeper MM, Markevych I, Spiekerkoetter E et al. Goal-oriented treatment and combination therapy for pulmonary arterial hypertension. Eur Respir J. 2005;26:858-63.

28. McLaughlin VV, Gaine SP, Howard LS et al. Treatment goals of pulmonary hypertension. J Am Coll Cardiol. 2013;62:D73-81.

29. Barst RJ, Rubin LJ, Long WA et al. A comparison of continuous intravenous epoprostenol (prostacyclin) with conventional therapy for primary pulmonary hypertension. N Engl J Med. 1996;334:296-301.

30. Sitbon O, Jais X, Savale L et al. Upfront triple combination therapy in pulmonary arterial hypertension: a pilot study. Eur Respir J. 2014;43:1691-7.

31. Galie N, Barbera JA, Frost AE et al. Initial use of ambrisentan plus tadalafil in pulmonary arterial hypertension. N Engl J Med. 2015;373:834-44.

32. Fox BD, Shimony A, Langleben D. Meta-analysis of monotherapy versus combination therapy for pulmonary arterial hypertension. Am J Cardiol. 2011;108:1177-82.

33. Bai Y, Sun L, Hu S et al. Combination therapy in pulmonary arterial hypertension: a meta-analysis. Cardiology. 2011;120:157-65.

34. Humbert M, Barst RJ, Robbins IM et al. Combination of bosentan with epoprostenol in pulmonary arterial hypertension: BREATHE-2. Eur Respir J. 2004;24:353-9.

35. Simonneau G, Rubin LJ, Galie N et al. Addition of sildenafil to long-term intravenous epoprostenol therapy in patients with pulmonary arterial hypertension: a randomized trial. Ann Intern Med. 2008;149:521-30.

36. Pulido T, Rubin LJ, Simonneau G. Macitentan and pulmonary arterial hypertension. N Engl J Med. 2014;370:82-3.

37. Ghofrani HA, Galie N, Grimminger F et al. Riociguat for the treatment of pulmonary arterial hypertension. N Engl J Med. 2013;369:330-40.

38. Galie N, Muller K, Scalise AV et al. PATENT PLUS: a blinded, randomised and extension study of riociguat plus sildenafil in pulmonary arterial hypertension. Eur Respir J. 2015;45:1314-22.

39. McLaughlin V, Channick RN, Ghofrani HA et al. Bosentan added to sildenafil therapy in patients with pulmonary arterial hypertension. Eur Respir J. 2015;46:405-13.

40. Pfizer. Assess the efficacy and safety of sildenafil when added to bosentan in the treatment of pulmonary arterial hypertension, 2014. NCT00323297. Available at: https:// clinicaltrials.gov/ct2/show/NCT00323297.

41. Asaki T, Kuwano K, Morrison K et al. Selexipag: An oral and selective IP prostacyclin receptor agonist for the treatment of pulmonary arterial hypertension. J Med Chem. 2015;58:7128-37.

42. Morrison K, Studer R, Ernst R et al. Differential effects of Selexipag and prostacyclin analogs in rat pulmonary artery. J Pharmacol Exp Ther. 2012;343:547-55. 
43. Sitbon O, Channick R, Chin KM et al. Selexipag for the treatment of pulmonary arterial hypertension: results of the GRIPHON study. N Eng J Med. 2015;373:2522-33.

44. Kim NH, Delcroix M, Jenkins DP et al. Chronic thromboembolic pulmonary hypertension. J Am Coll Cardiol. 2013;62:D92-9.

45. Pepke-Zaba J, Delcroix M, Lang I et al. Chronic thromboembolic pulmonary hypertension (CTEPH): results from an international prospective registry. Circulation. 2011;124:1973-81.

46. Guerin L, Couturaud F, Parent F et al. Prevalence of chronic thromboembolic pulmonary hypertension after acute pulmonary embolism. Prevalence of CTEPH after pulmonary embolism. Thromb Haemost. 2014; 112:598-605.

47. Klok FA, van Kralingen KW, van Dijk AP et al. Prospective cardiopulmonary screening program to detect chronic thromboembolic pulmonary hypertension in patients after acute pulmonary embolism. Haematologica. 2010;95:970-5.

48. Poli D, Grifoni E, Antonucci E et al. Incidence of recurrent venous thromboembolism and of chronic thromboembolic pulmonary hypertension in patients after a first episode of pulmonary embolism. J Thromb Thrombolysis. 2010;30:294-9.

49. Pengo V, Lensing AW, Prins MH et al. Incidence of chronic thromboembolic pulmonary hypertension after pulmonary embolism. N Engl J Med. 2004;350:2257-64.

50. Pepke-Zaba J, Hoeper MM, Humbert M. Chronic thromboembolic pulmonary hypertension: advances from bench to patient management. Eur Respir J. 2013;41:8-9.

51. Moser KM, Bloor CM. Pulmonary vascular lesions occurring in patients with chronic major vessel thromboembolic pulmonary hypertension. Chest. 1993;103:685-92.

52. Tunariu N, Gibbs SJ, Win Z et al. Ventilation-perfusion scintigraphy is more sensitive than multidetector CTPA in detecting chronic thromboembolic pulmonary disease as a treatable cause of pulmonary hypertension. J Nucl Med. 2007;48:680-4

53. Lang IM, Madani M. Update on chronic thromboembolic pulmonary hypertension. Circulation. 2014;130:508-18.

54. Hoeper MM, Madani MM, Nakanishi N et al. Chronic thromboembolic pulmonary hypertension. Lancet Respir Med. 2014;2:573-82.

55. Madani MM, Auger WR, Pretorius V et al. Pulmonary endarterectomy: recent changes in a single institution's experience of more than 2,700 patients. Ann Thorac Surg. 2012;94:97-103.

56. Mayer E, Klepetko W. Techniques and outcomes of pulmonary endarterectomy for chronic thromboembolic pulmonary hypertension. Proc Am Thorac Soc. 2006;3:589-93.

57. Taboada D, Pepke-Zaba J, Jenkins DP et al. Outcome of pulmonary endarterectomy in symptomatic chronic thromboembolic disease. Eur Respir J. 2014;44:1635-45.

58. Mayer E, Jenkins D, Lindner J et al. Surgical management and outcome of patients with chronic thromboembolic pulmonary hypertension: results from an international prospective registry. J Thorac Cardiovasc Surg. 2011;141:702-10.

59. Ghofrani HA, D'Armini AM, Grimminger F et al. Riociguat for the treatment of chronic thromboembolic pulmonary hypertension. N Engl J Med. 2013;369:319-29.
60. Simonneau G, D'Armini AM, Ghofrani HA et al. Riociguat for the treatment of chronic thromboembolic pulmonary hypertension: a long-term extension study (CHEST-2). Eur Respir J. 2015;45:1293-302.

61. Suntharalingam J, Treacy CM, Doughty NJ et al. Long-term use of sildenafil in inoperable chronic thromboembolic pulmonary hypertension. Chest. 2008;134:229-36.

62. Jais X, D'Armini AM, Jansa P et al. Bosentan for treatment of inoperable chronic thromboembolic pulmonary hypertension: BENEFiT (Bosentan Effects in iNopErable Forms of chronIc Thromboembolic pulmonary hypertension) a randomized, placebo-controlled trial. J Am Coll Cardiol. 2008;52:2127-34.

63. Feinstein JA, Goldhaber SZ, Lock JE et al. Balloon pulmonary angioplasty for treatment of chronic thromboembolic pulmonary hypertension. Circu lation. 2001;103:10-13.

64. Mizoguchi H, Ogawa A, Munemasa M et al. Refined balloon pulmonary angioplasty for inoperable patients with chronic thromboembolic pulmonary hypertension. Circ Cardiovasc Interv. 2012;5:748-55.

65. Inami T, Kataoka M, Shimura N et al. Pressure-wire-guided percutaneous transluminal pulmonary angioplasty: a breakthrough in catheter-interventional therapy for chronic thromboembolic pulmonary hypertension. JACC Cardiovasc Interv. 2014;7:1297-306.

66. Kataoka M, Inami T, Hayashida K et al. Percutaneous transluminal pulmonary angioplasty for the treatment of chronic thromboembolic pulmonary hypertension. Circ Cardiovasc Interv. 2012;5:756-62.

67. Fukui S, Ogo T, Goto $Y$ et al. Exercise intolerance and ventilatory inefficiency improve early after balloon pulmonary angioplasty in patients with inoperable chronic thromboembolic pulmonary hypertension. Int J Cardiol. 2015;180:66-8

68. Andreassen AK, Ragnarsson A, Gude E et al. Balloon pulmonary angioplasty in patients with inoperable chronic thromboembolic pulmonary hypertension. Heart. 2013;99:1415-20.

69. Taniguchi Y, Miyagawa K, Nakayama K et al. Balloon pulmonary angioplasty: an additional treatment option to improve the prognosis of patients with chronic thromboembolic pulmonary hypertension. EuroIntervention. 2014;10:518-25.

70. McLaughlin VV, Oudiz R, Frost A et al. Randomized study of adding inhaled iloprost to existing bosentan in pulmonary arterial hypertension. Am J Resp Crit Care Med. 2006;174:1257-63.

71. Hoeper MM, Leuchte H, Halank M et al. Combining inhaled iloprost with bosentan in patients with idiopathic pulmonary arterial hypertension. Eur Respir J. 2006;28:691-4.

72. McLaughlin VV, Benza RL, Rubin LJ et al. Addition of inhaled treprostinil to oral therapy for pulmonary arterial hypertension: A randomized controlled clinical trial. J Am Coll Cardiol. 2010;55:1915-22.

73. Tapson VF, Torres F, Kermeen F et al. Oral treprostinil for the treatment of pulmonary arterial hypertension in patients on background endothelin receptor antagonist and/or phosphodiesterase type 5 inhibitor therapy (the FREEDOM-C study): a randomized controlled trial. Chest. 2012;142:1383-90.

74. Tapson VF, Jing ZC, Xu KF et al. Oral treprostinil for the treatment of pulmonary arterial hypertension in patients receiving background endothelin receptor antagonist and phosphodiesterase type 5 inhibitor therapy (the FREEDOM-C2 study): A randomized controlled trial. Chest. 2013;144:952-8

75. Galie N, Brundage BH, Ghofrani HA et al. Tadalafil therapy for pulmonary arterial hypertension. Circulation. 2009;119:2894-903. 